TP Periodica Polytechnica Chemical Engineering

\author{
62(3), pp. 317-322, 2018 \\ https://doi.org/10.3311/PPch.11676 \\ Creative Commons Attribution (i)
}

RESEARCH ARTICLE

\section{Assessment of the Influence of Graphene Nanoparticles on Thermal Conductivity of Graphene/Water Nanofluids Using Factorial Design of Experiments}

\author{
Srinivasan Periasamy Manikandan ${ }^{1 *}$, Rajoo Baskar $^{2}$
}

Received 03 November 2017; accepted after revision 25 January 2018

\begin{abstract}
In this study, $2^{3}$ factorial design of experiment was employed to evaluate the effect of parameters of hot fluid inlet temperature, graphene nanofluid concentration and hot fluid flow rate on thermal conductivity of graphene/water nanofluid. The levels of hot fluid inlet temperature are kept at $35^{\circ} \mathrm{C}$ and $85^{\circ} \mathrm{C}$, nanofluid concentration is kept at 0.1 and 1.0 volume\% (vol.\%) and the hot fluid flow rate are kept at $2 \mathrm{lpm}$ and $10 \mathrm{lpm}$. Experiments were conducted with 16 runs as per MINITAB design software using graphene/water nanofluids in the corrugated plate type heat exchanger. The nanofluid thermal conductivity was determined using the mixing rule for different nanofluid concentrations ranging from 0.1 to $1.0 \%$. Normal, Pareto, Residual, Main and Interaction effects, Contour Plots were drawn. The Analysis of Variance (ANOVA) of test results depict that the hot fluid temperature and nanofluid concentration have significant effect on the thermal conductivity of graphene/water nanofluid (response variable).
\end{abstract}

\section{Keywords}

design of experiment, factorial design, graphene/water nanofluids, thermal conductivity

\footnotetext{
${ }^{1}$ Department of Chemical Engineering,

Kongu Engineering College,

Erode, India-638060

${ }^{2}$ Department of Food Technology,

Kongu Engineering College,

Erode, India-638060
}

*Corresponding author, e-mail: sriperiasamy@gmail.com

\section{Introduction}

Heat transfer plays an important role in the processing of various products influencing cost, rate of production and product quality. Heat transfer enhancement in any industrial processes may results in significant energy savings. From the energy point of view it is important to reduce the energy consumption by modifying the production method or upgrading the equipment used for the above purpose. In industry, designed experiments can be used to systematically investigate the process or product variables that influence product quality. Plate heat exchangers are used frequently in the diary, food and process industries. The advantages of plate heat exchanger include their higher efficiency, compactness and less weight when compared to the shell and tube heat exchanger for the same capacity. Many studies being carried out for the purpose of enhancing the heat transfer using metal and metal oxide nanoparticles. In a given fluid, the colloidal suspension of stable nanoparticle gives more heat transfer enhancement [1]. Zamzamian et al. [2] investigated the heat transfer performance of $\mathrm{Al}_{2} \mathrm{O}_{3}$ /ethylene glycol and $\mathrm{CuO} /$ ethylene glycol nanofluids in a plate heat exchanger and described that, the heat transfer coefficient increased with temperature and vol. \% of nanoparticles. Haghshenas et al. [3] examined the plate and concentric tube heat exchangers by using $\mathrm{ZnO} /$ water nanofluids as the hot stream at a constant mass flow rate, and concluded that the heat transfer coefficients of nanofluids were much higher than those of the distilled water. The thermal conductivity of SiC particles dispersed in EG/W measured by Xie et al.[4] showed a $22.9 \%$ enhancement at a $4 \%$ volumetric concentration. Vajjha et al. [5] measured the thermal conductivity of three different $\left(\mathrm{Al}_{2} \mathrm{O}_{3}, \mathrm{ZnO}, \mathrm{CuO}\right)$ 60:40 EG/W nanofluids. They found that thermal conductivity of nanofluids increased with volume concentration.

Timofeeva et al. [6] used alumina nanofluids and showed that the geometry of nanoparticles and agglomerates plays a major role in determining the thermal conductivity enhancement in effective medium theory. Duangthongsuk and Wongwises [7] studied the temperature dependency of $\mathrm{TiO}_{2}$-Water nanofluid in the range of 0.2 to 2 vol. $\%$ and temperature range $15^{\circ} \mathrm{C}$ to $35^{\circ} \mathrm{C}$. Their results revealed that increasing volume fraction 
and temperature increases thermal conductivity. The performance of a plate heat exchanger using nanofluids was studied by Pantzali et al. [8]. Balla et al. [9] performed the numerical study of the enhancement of heat transfer for hybrid copper based nanofluids flowing in a circular pipe with constant heat flux. The thermal conductivity of $\mathrm{Fe}_{3} \mathrm{O}_{4}$ nanoparticles were investigated experimentally by SyamSundar [10] with ethylene glycol-water system at room temperature. Nizar Ahammed [11] studied measurement of thermal conductivity of graphenewater nanofluid using a transient hot wire technique at temperatures below and above ambient conditions ranging from $10{ }^{\circ} \mathrm{C}$ to $50{ }^{\circ} \mathrm{C}$. The results showed an enhancement in the thermal conductivity of $37.2 \%$ for $0.15 \%$ volume concentration of graphene at $50{ }^{\circ} \mathrm{C}$ when compared with that of the water at the same temperature. Wang et al. [12] used Steady-state method to measure thermal conductivity of $\mathrm{Al}_{2} \mathrm{O}_{3}$ /ethylene glycol nanofluids. Lambda Instruments was used by Aravind et al. [13] for the measurement of thermal conductivity of MWCNT nano particles over ethylene glycol.

Several studies comprising of application of nanofluids in heat transfer for improving their efficiency have been found in the literature. However, the works related to the application of factorial design methods to determine the influence of various factors on the thermal conductivity of nanofluids are not often found in literature. This paper highlights application of the principles of $2^{3}$ factorial design with consideration of the factors hot fluid inlet temperature, graphene nanofluid concentration and hot fluid flow rate on thermal conductivity of graphene/water nanofluid. Moreover, Normal Plot, Pareto Chart, Residual Plots, Main Effects and Interaction Plots, Contour Plots were drawn with thermal conductivity of graphene/water nanofluids as a response factor.

\section{Experimental and statistical procedure \\ 2.1 Experimental setup}

The experimental set up consists of Hot water tank (20 L), Cold water tank (15 L), two pumps, two flow meters, four thermocouples and a corrugated Plate Heat Exchanger (PHE), which is shown in Fig. 1.

The inlet and outlet temperatures of hot and cold side fluids were measured. Rota meter was used to measure and control the flow rates.

\subsection{Determination of thermo physical properties}

After conducting experiments according to the various combinations of input parameters [14] given by MINITAB factorial design of experiments, the thermo physical properties of nanofluids were calculated from the correlations given in the equations from (1) to (4).

To evaluate the density ( $\rho$ ) of nanofluid, Pak and Cho's equation [15] is used as given below:

$$
\rho_{n f}=(1-\phi) \rho_{f}+\phi \rho_{P}
$$

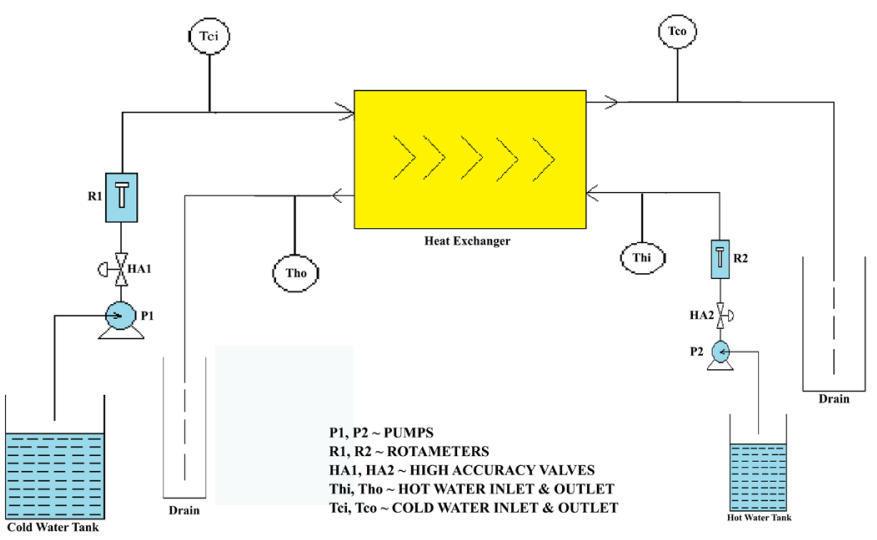

Fig. 1 Schematic representation of Experimental Setup

The specific heat capacity $\left(C_{p}\right)$ of nanofluid was calculated by Xuan and Roetzel's equation [16] as follows:

$$
\text { Cpnf }=\left((1-\phi) \rho_{f} C_{p f}+\phi \rho_{p} C_{p p}\right) /\left(\rho_{n f}\right)
$$

Einstein equation [17] can be used to determine the viscosity of fluids including spherical particles in less than 5\% volume concentrations:

$$
\mu_{n f}=(1+2.5 \phi) \mu_{f}
$$

To determine the thermal conductivity of nanofluid, Maxwell model [18] is used as follows:

$$
k_{n f}=\frac{\left(k_{p}+2 k_{f}+2 \phi\left(k_{p}-k_{f}\right)\right)}{\left(k_{p}+2 k_{f}-\phi\left(k_{p}-k_{f}\right)\right)}
$$

For all the calculations, the fluid properties are evaluated at bulk mean temperatures of hot and cold fluids.

\subsection{Experimental Design: Input parameters and their levels}

In a full factorial experiment, responses are measured at all combinations of the experimental factor levels. The combinations of factor levels represent the conditions at which responses will be measured [19]. Each experimental condition is called a "run" and the response measurement is an observation [20]. The entire set of runs is the "design". In the present study a $2^{3}$ (two-level, three-factors) full factorial design was employed with two replications [21]. This resulted in 8 unique experimental conditions with two replications each, which leaded to a total number of 16 runs. Table 1 provides the design summary for the study and Table 2 illustrates the controllable parameters and their respective levels used in the present study.

Table 1 Design summary for the study

\begin{tabular}{ll}
\hline Factors & 3 \\
\hline Base design & 3.8 \\
Number of experimental runs & 16 \\
Replicates & 2 \\
Blocks & 2 \\
\hline
\end{tabular}

S.Periasamy Manikandan, R.Baskar 
Table 2 Factor and Level for General factorial design

\begin{tabular}{lcc}
\hline \multirow{2}{*}{ Factor } & \multicolumn{2}{c}{ Level } \\
\cline { 2 - 3 } & low & high \\
\hline hot fluid inlet temperature, ${ }^{\circ} \mathrm{C}$ ( A ) & 35 & 85 \\
nanofluid concentration, \% ( B ) & 0.1 & 1.0 \\
hot fluid flow rate, lpm ( C ) & 2 & 10 \\
\hline
\end{tabular}

\subsection{Data analysis}

MINITAB software was used to generate the testing order and to assist in processing the experimental data. Statistical analysis was performed in order to investigate the significance of the input variables and their interactions on the output response. The ANOVA was adopted for testing the significance of main effects and interaction on response. Table 3 exhibits the design layout and experimental results of $2^{3}$ factorial design.

Table 3 Design layout and experimental results of full factorial design

\begin{tabular}{|c|c|c|c|c|c|}
\hline \multirow{2}{*}{$\begin{array}{l}\text { Standard } \\
\text { order }\end{array}$} & \multirow{2}{*}{ Run order } & \multicolumn{3}{|c|}{ Factorial input variable } & \multirow{2}{*}{$\begin{array}{c}\text { Response } \\
\text { variable } \\
\mathrm{k}_{\mathrm{nf},} \mathrm{W} / \mathrm{m} \mathrm{K} \\
\end{array}$} \\
\hline & & A & B & $\mathrm{C}$ & \\
\hline 1 & 4 & 85 & 1.0 & 2 & 0.708 \\
\hline 2 & 1 & 35 & 0.1 & 2 & 0.610 \\
\hline 3 & 3 & 35 & 1.0 & 2 & 0.622 \\
\hline 4 & 5 & 35 & 0.1 & 10 & 0.620 \\
\hline 5 & 7 & 35 & 1.0 & 10 & 0.642 \\
\hline 6 & 6 & 85 & 0.1 & 10 & 0.660 \\
\hline 7 & 8 & 85 & 1.0 & 10 & 0.722 \\
\hline 8 & 2 & 85 & 0.1 & 2 & 0.662 \\
\hline 9 & 15 & 35 & 1.0 & 10 & 0.618 \\
\hline 10 & 14 & 85 & 0.1 & 10 & 0.658 \\
\hline 11 & 12 & 85 & 1.0 & 2 & 0.708 \\
\hline 12 & 9 & 35 & 0.1 & 2 & 0.615 \\
\hline 13 & 11 & 35 & 1.0 & 2 & 0.624 \\
\hline 14 & 10 & 85 & 0.1 & 2 & 0.662 \\
\hline 15 & 16 & 85 & 1.0 & 10 & 0.728 \\
\hline 16 & 13 & 35 & 0.1 & 10 & 0.618 \\
\hline
\end{tabular}

The observed thermal conductivity values of graphene/water nanofluids were compared with the different metal and metal oxide nanofluid thermal conductivities presented in a literature. It is observed from the literarure study that the thermal conductivity increases with an increase in temperature and volume concentration of nanoparticles; a similar trend has also been noticed by our study. From the results of researchers, it is observed that graphene/water nanofluids has higher thermal conductivity than meatal oxide nanofluids such as $\mathrm{Fe}_{3} \mathrm{O}_{4}$ /water [10], $\mathrm{Al}_{2} \mathrm{O}_{3}$ /water [22] and $\mathrm{TiO}_{2}$ /water [23]. But most of the metal nanofluids such as $\mathrm{Cu} /$ water [24] and $\mathrm{Ag} /$ water [25] have a higher thermal conductivity value than graphene/water nanofluids. This is due to the high energy free electrons, rapid molecular collisions and boundary diffusions lead to higher thermal conductivity due to suspension of solid nano particles. However, the use of pure metallic nanoparticles in fluids causes the problems of stability issues. Hence it is suggested that instead of using a high volume concentration of metal oxide and pure metal nano particles, a low volume concentration of graphene can be used as the heat transfer fluid for enhancing the thermal conductivity.

\section{Results and Discussion}

\subsection{Standardized Effects for thermal conductivity of graphene/water nanofluids using Normal Plot and Pareto Chart}

Normal Plot and Pareto Chart of the standardized effects are obtained to compare the significance of each effect [26]. Fig. 2 (a) and Fig. 2 (b) demonstrates the Standardized Effects Plots for the response thermal conductivity of graphene/water nanofluids. According to the Normal Probability Plots, Important effects are larger and further from the fitted line than unimportant effects. Points far away from the line likely represent the "real" fact or effects [27]. A Pareto Chart can be constructed by segmenting the range of the data into group. The relative importance of the effects to compare the relative magnitude and the statistical significance of both main effects and their interactions is also observed on the Pareto Chart. Any effect that extends past this reference line is potentially important.

Hence Normal Plot and Pareto Chart of the Standardized Effects shows that the terms A, B and AB (Interaction of A and B) are significant, ie., the factors hot fluid inlet temperature (A), nanofluid concentration(B) and interaction of AB are significant, however the hot fluid flow rate (C) is not significant for thermal conductivity.

\subsection{Residual Plots for thermal conductivity of graphene/water nanofluid}

The Residual Plots for thermal conductivity of graphene/ water nanofluid are illustrated in Fig. 3, which shows the normality of the data and that the other assumptions of the test are being met . The Plot of normal probability shows if residuals follow a normal and independent distribution. In this plot, points must follow a straight line . By considering Fig. 3, it is observed that error values related to response variable of thermal conductivity are almost along with the straight normal line and it shows the error distribution is normal.

\subsection{ANOVA analysis}

Analysis of Variance (ANOVA) on the thermal conductivity of graphene/water nanofluid was used to check the significance of the model [28]. Table 4 shows the statistical results of the thermal conductivity of graphene/water nanofluid obtained using ANOVA. 
(a)

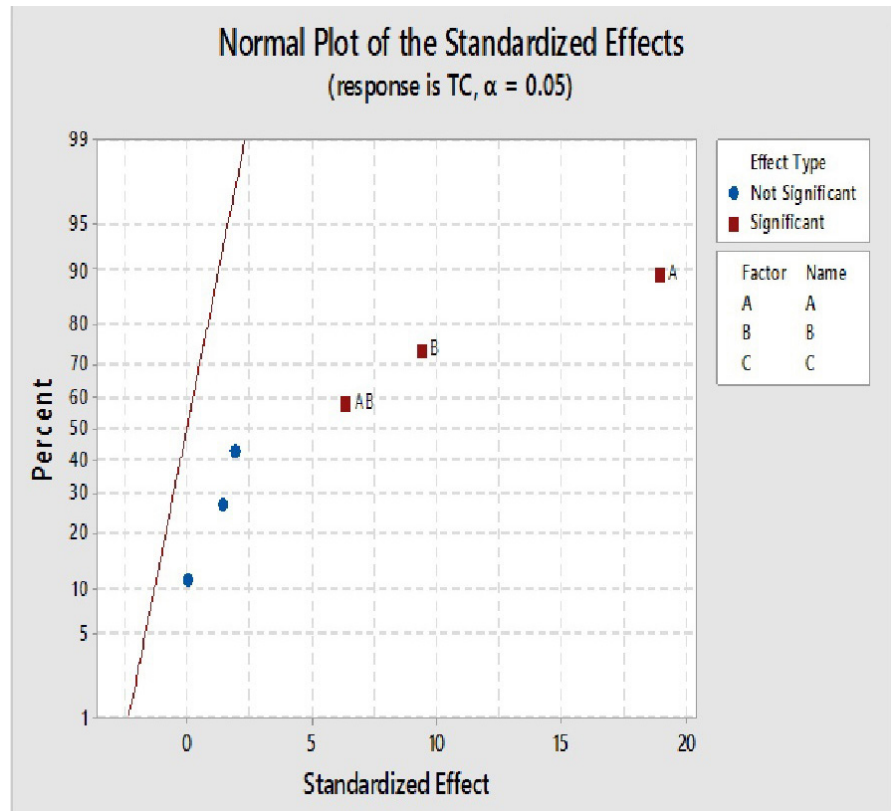

(b)

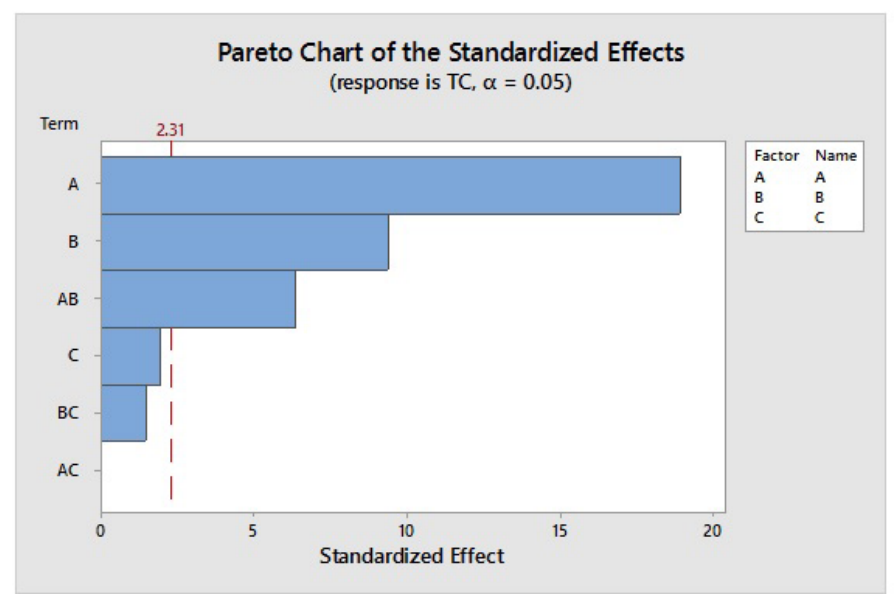

Fig. 2 (a) Standardized effects for thermal conductivity of graphene/water nanofluid (b) Standardized effects for thermal conductivity of graphene/water nanofluid using Pareto Chart

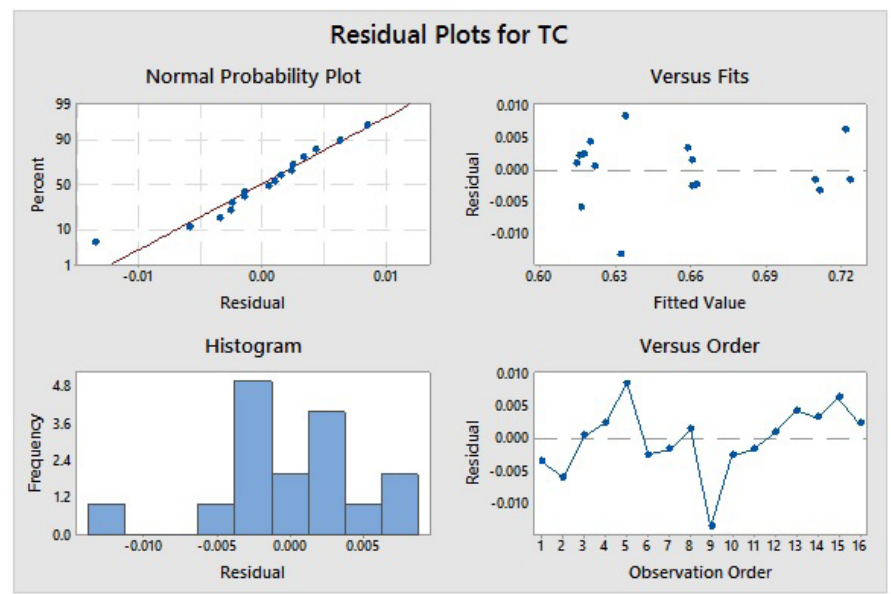

Fig. 3 The Residual Plots for thermal conductivity of graphene/water nanofluid
$\mathrm{R}^{2}$ value closer to 1 indicates a good fit model based on good data [29]. The $\mathrm{R}$ square in this study was 0.984 that showed this model could account for over 0.984 of the variability in the response. The adjusted $R$-squared $\left(\mathrm{R}^{2}\right.$-adj) were also very high (0.97), which confirms that the model is highly significant [30]. Also, the R-squared $\left(R^{2}\right)$ and the adjusted R-squared $\left(R^{2}\right.$-adj) are close to each other, which show that the model does not include insignificant parameters.

Table 4 Analysis of variance (ANOVA) for selected factorial model

\begin{tabular}{|c|c|c|c|c|c|c|}
\hline Source & DF & $\begin{array}{c}\text { Adj } \\
\text { SS } \\
\times 10^{-2}\end{array}$ & $\begin{array}{c}\text { Adj } \\
\text { MS } \\
\times 10^{-2}\end{array}$ & F-Value & P-Value & $\begin{array}{c}\text { model } \\
\text { significance }\end{array}$ \\
\hline Model & 7 & 2.490 & 0.35 & 70.4 & 0.00 & significant \\
\hline Blocks & 1 & 0.001 & 0 & 0.28 & 0.61 & $\begin{array}{c}\text { not } \\
\text { significant }\end{array}$ \\
\hline Linear & 3 & 2.280 & 0.76 & 150 & 0.00 & significant \\
\hline A & 1 & 1.815 & 1.81 & 358 & 0.00 & significant \\
\hline B & 1 & 0.445 & 0.44 & 88 & 0.00 & significant \\
\hline $\mathrm{C}$ & 1 & 0.019 & 0.01 & 3.73 & 0.09 & $\begin{array}{c}\text { not } \\
\text { significant }\end{array}$ \\
\hline $\begin{array}{l}\text { 2-Way } \\
\text { Interactions }\end{array}$ & 3 & 0.215 & 0.07 & 14.2 & 0.00 & significant \\
\hline$A * B$ & 1 & 0.205 & 0.20 & 40.4 & 0.00 & significant \\
\hline$A * C$ & 1 & 0 & 0 & 0 & 0.97 & $\begin{array}{c}\text { not } \\
\text { significant }\end{array}$ \\
\hline $\mathrm{B}^{*} \mathrm{C}$ & 1 & 0.105 & 0.01 & 2.07 & & $\begin{array}{c}\text { not } \\
\text { significant }\end{array}$ \\
\hline Error & 8 & 0.041 & 0 & & & \\
\hline Total & 15 & 2.537 & & & & \\
\hline R-sq $\left(\mathrm{R}^{2}\right)$ & 0.98 & & & & & \\
\hline R-sq(adj) & 0.97 & & & & & \\
\hline
\end{tabular}

\subsection{Effects of operating conditions}

The analysis of variance table gives a summary of the main effects and interactions. MINITAB displays both the sequential sums of squares (Seq SS) and adjusted sums of squares (Adj SS). A main effect occurs when the mean response changes across the levels of a factor. Main Effects Plots are used to compare the relative strength of the Effects across factors. Fig. 4(a) and Fig. 4 (b) show the Main Effects and interactions of the hot fluid inlet temperature and nanofluid concentration on thermal conductivity of graphene/water nanofluids.

\subsection{Contour Plots}

The Contour Plots indicate that the highest thermal conductivity is obtained when hot fluid inlet temperature and nanofluid concentration are high. This area appears at the upper right corner of the plot. Fig. 5 shows the Contour Plots that show the interaction effect of hot fluid inlet temperature (A) and nanofluid concentration (B) on thermal conductivity. As 

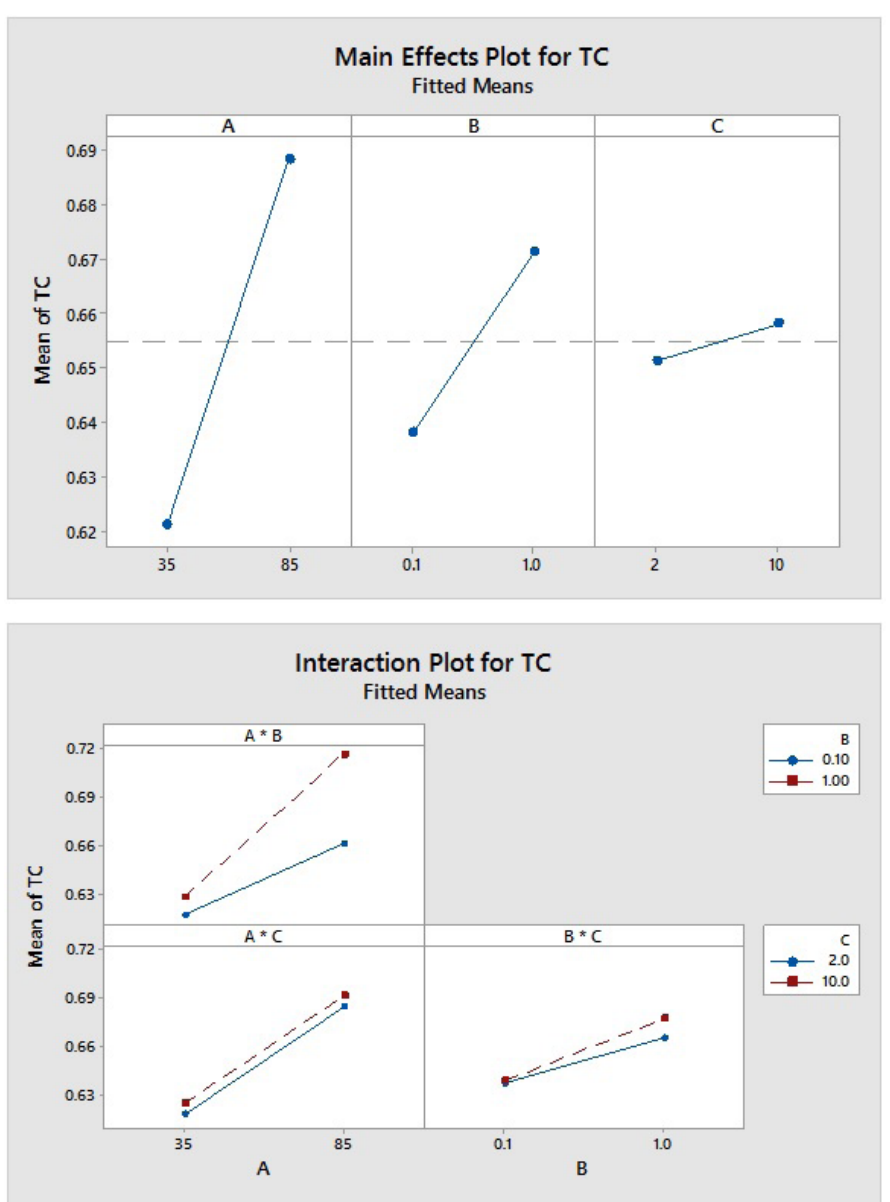

Fig. 4 (a) Main Effects plots for thermal conductivity of graphene/water nanofluid (b) Interaction Plots for thermal conductivity of graphene/water nanofluid
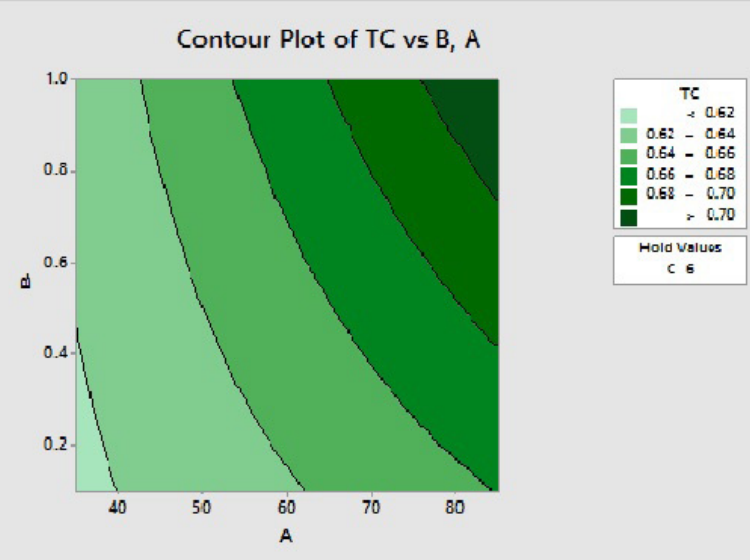

Fig 5 Contour Plot of hot fluid inlet temperature and nanofluid concentration on thermal conductivity of graphene/water nanofluid

can be observed, by increasing A and B, the thermal conductivity has an increasing pattern.

The figure also shows that that the descending trend of thermal conductivity with nanoparticle concentration is more noticeable at the higher levels of nanofluid concentration. At higher temperatures, the random motions of nanoparticles go up and cause the energy transferred faster inside the nanofluid.

\section{Conclusion}

In this research, thermal conductivity of graphene/water nanofluid was examined by $2^{3}$ factorial design by using MINITAB software. In order to find the effects of thermal conductivity of nanofluids, three factors with two levels of $35^{\circ} \mathrm{C}$ and $85^{\circ} \mathrm{C}, 0.1$ and $1.0 \%$ and $2 \mathrm{lpm}$ and $10 \mathrm{lpm}$ were considered for hot fluid inlet temperature, nanofluid concentration and hot fluid flow rate respectively. The use of factorial design allowed for identification of the most significant factor under test conditions. ANOVA revealed the hot fluid inlet temperature and nanofluid concentration have significant effects on the thermal conductivity and the hot fluid flow rate has no significant effect on the thermal conductivity of graphene/water nanofluids. Normal Plot, Pareto Chart, Residual Plots, Main Effects and Interaction Plots, Contour Plots were drawn with thermal conductivity of graphene/water nanofluids as a response factor. As volume concentrations and hot fluid inlet temperatures increased, the thermal conductivity increased significantly. The maximum thermal conductivity obtained in our study is 0.728 $\mathrm{W} / \mathrm{m} \mathrm{K}$ for graphene/water nanofluids at the hot fluid inlet temperature of $85^{\circ} \mathrm{C}$ and nanofluid concentration of $1.0 \mathrm{Vol} \%$.

\section{Nomenclature}

$\begin{array}{ll}\text { lpm } & \text { litres per minute } \\ \text { Cp } & \text { specific heat capacity, J/(kg K) } \\ \text { PHE } & \text { Plate Heat Exchanger } \\ \text { vol. \% } & \text { Volume \% } \\ \text { MWCNT } & \text { Multi Walled Carbon Nano Tubes } \\ \text { reek symbols }\end{array}$

k thermal conductivity, $\mathrm{W} /(\mathrm{m} \mathrm{K})$

$\mu \quad$ dynamic viscosity, Pa s

$\rho \quad$ density, $\mathrm{kg} / \mathrm{m}^{3}$

$\varnothing \quad$ nanoparticle volume fraction, dimensionless

\section{Subscripts}

$\begin{array}{ll}\text { nf } & \text { nanofluid } \\ \mathrm{f} & \text { basefluid } \\ \mathrm{p} & \text { nanoparticle }\end{array}$

\section{References}

[1] Choi, S. U. S., Lee, S., Li, S., Eastman, J. A. "Measuring Thermal Conductivity of Fluids containing oxide nano particles." Journal of Heat Transfer. 121, pp. 280-289. 1999. https://doi.org/10.1115/1.2825978

[2] Zamzamian, A., Oskouie, S. N., Doosthoseini, A., Joneidi, A., Pazouki, M. "Experimental investigation of forced convection heat transfer coefficient in nanofluids of $\mathrm{Al} 2 \mathrm{O} / \mathrm{EG}$ and $\mathrm{CuO} / \mathrm{EG}$ in a double pipe and plate heat exchangers under turbulent flow." Experimental Thermal and Fluid Science. 35, pp. 495-502. 2011.

https://doi.org/10.1016/j.expthermflusci.2010.11.013

[3] Haghshenas, F. M., Talaie, M. R., Nasr, S. "Numerical and experimental investigation of heat transfer of $\mathrm{ZnO} /$ water nanofluid in the concentric tube and plate heat exchangers." Thermal Science. 15(1), pp. 183-194. 2011. https://doi.org/10.2298/TSCI091103048H 
[4] Xie, H., Wang, J., Xi, T., Liu, Y. "Thermal conductivity of suspensions containing nanosized $\mathrm{SiC}$ particles." International Journal of Thermophysics. 23(2), pp. 571-580. 2002.

https://doi.org/10.1023/A:1015121805842

[5] Vajjha, R. S., Das, D. K. "Experimental determination of thermal conductivity of three nanofluids and development of new correlations." International Journal of Heat and Mass Transfer. 52, pp. 4675-4682. 2009.

https://doi.org/10.1016/j.ijheatmasstransfer.2009.06.027

[6] Timofeeva, E. V., Gavrilov, A. N., Mccloskey, J. M., Tolmachev, Y. V., Sprunt, S., Lopatina, L.M., Selinger, J. V. "Thermal Conductivity and particle agglomeration in alumina nano fluids: experiment and theory." Physical Review. 76(6), 2007.

https://doi.org/10.1103/PhysRevE.76.061203

[7] Weerapun, D., Wongwisess, S. "Measurement of temperature-dependant thermal conductivity and viscosity of $\mathrm{TiO}_{2}$-water nano fluids." Experimental Thermal Fluid Science. 33, pp. 706-714. 2009.

https://doi.org/10.1016/j.expthermflusci.2009.01.005

[8] Pantali, M. N., Kanaris, A. G., Antoniadis, K. D., Mouza, A. A., Paras, S. V. "Effect of nanofluids on the performance of a miniature plate heat exchanger with modulated surface." International Journal of Heat Fluid Flow. 30, pp. 691-699. 2009.

https://doi.org/10.1016/j.ijheatfluidflow.2009.02.005

[9] Balla, H. H., Abdulla, S., Wan, M. F., Zulkifli, R., Sopian, K. "Numerical study of the enhancement of heat transfer for hybrid $\mathrm{CuO}-\mathrm{Cu}$ nanofluids flowing in a circular pipe." Journal of Oleo Science. 62(7), pp. 533-539. 2013

https://doi.org/10.5650/jos.62.533

[10] Syam Sundar, L., Manoj, K., Singh, A., Sousa, C. M. "Thermal conductivity of ethylene glycol and water mixture based $\mathrm{Fe}_{3} \mathrm{O}_{4}$ nanofluid." International Communications in Heat Mass Transfer. 49, pp.17-24. 2013.

https://doi.org/10.1016/j.icheatmasstransfer.2013.08.026

[11] Ahmed, N., Asirvatham, L. G., Titus, J., Bose, J. R., Wongwises, S. "Measurement of thermal conductivity of graphene-water nanofluid at below and above ambient temperatures." International Communications in Heat Mass Transfer. 70, pp. 66-74. 2016.

https://doi.org/10.1016/j.icheatmasstransfer.2015.11.002

[12] Wang, X., Xu, X., Choi, S. U. S. "Thermal conductivity of nanoparticlefluid mixture." Journal of Thermophysics and Heat Transfer. 13, pp. 474-480. 1999.

https://doi.org/10.2514/2.6486

[13] Aravind, S. S. J., Baskar, P., Baby, T. T., Sabareesh, R. K., Das, S., Ramaprabhu, S. "Investigation of structural stability, dispersion, viscosity, and conductive heat transfer properties of functionalized carbon nanotube based nanofluids." Journal of Physical Chemistry. 115, pp. 16737-16744. 2011

https://doi.org/10.1021/jp201672p

[14] Rahmanian, B., Pakizeh, M., Mansoori, S. A. A., Abedini, R. "Application of Experimental Design Approach and Artificial Neural Network (ANN) for the determination of potential Micellar - Enhanced Ultrafiltration Process." Journal of Hazardous Materials. 187, pp. 67-74. 2011. https://doi.org/10.1016/j.jhazmat.2010.11.135

[15] Vajjha, R. S., Das, D. K., Mahagaonkar, B. M. "Density measurement of different nanofluids and their comparison with theory." Petroleum Science and Technology. 27, pp. 612-624. 2009. https://doi.org/10.1080/10916460701857714

[16] Xuan, Y., Roetzel,W. "Conceptions for heat transfer correlation of nanofluids." International Journal of Heat and Mass Transfer. 43, pp. 37013707. 2000

https://doi.org/10.1016/S0017-9310(99)00369-5
[17] Sahoo, B. C., Vajjha, R. S., Ganguli, R., Chukwu, G. A., Das, D. K. "Determination of rheological behavior of aluminum oxide nano fluid and development of new viscosity correlations." Petroleum Science and Technology. 27(15), pp. 1757-1770. 2009. https://doi.org/10.1080/10916460802640241

[18] Koo, J., Kleinstreuer, C. "A new thermal conductivity model for nanofluids." Journal of Nanoparticle Research. 6, pp. 577-588. 2004. https://doi.org/10.1007/s11051-004-3170-5

[19] Nair, V. N., Pregibon, D. "Analyzing Dispersion Effects from Replicated Factorial Experiments." Technometrics. 30, pp. 247-257. 1988. https://doi.org/10.1080/00401706.1988.10488398

[20] Box, G. E. P., Hunter, W. G., Hunter, J. S. "Statistics for Experimenters. An Introduction to Design, Data Analysis, and Model Building." John Wiley \& Sons, New York. 1978. https://doi.org/10.1118/1.595008

[21] Lenth, R. V. "Quick and Easy Analysis of Unreplicated Factorials." Technometrics. 31, pp. 469-473. 1989. https://doi.org/10.2307/1269997

[22] Ghanbarpour, M., Bitaraf Haghigi, E., Khodabandeh, R. "Thermal properties and rheological behavior of water based $\mathrm{Al} 2 \mathrm{O} 3$ nanofluid as a heat transfer fluid." Experimental Thermal and Fluid Science. 53, pp. 227235. 2014.

https://doi.org/10.1016/j.expthermflusci.2013.12.013

[23] Yiamsawasd, T., Dalkilic, A. S., Wongwises, S. "Measurement of thermal conductivity of titania and alumina nanofluids." Thermochimica Acta. 545, pp. 48-56. 2012.

https://doi.org/10.1016/j.tca.2012.06.026

[24] Liu, M. M., Lin, M., Tsai, C. Y., Wang, C. C. "Enhancement of thermal conductivity with $\mathrm{Cu}$ for nanofluids using chemical reduction method." International Journal of Heat and Mass Transfer. 49, pp. 3028-3033. 2006. https://doi.org/10.1016/j.ijheatmasstransfer.2006.02.012

[25] Godson, L., Lal, D. M., Wongwises, S. "Measurement of thermo physical properties of metallic nanofluids for high temperature applications." Nanoscale Microscale Thermophysical Engineering. 14(3), pp. 152-173. 2010.

https://doi.org/10.1080/15567265.2010.500319

[26] Pan, G. "The impact of Unidentified Location Effects on DispersionEffects Identification from Un replicated Factorial Designs." Technometrics. 41, pp. 313-326. 1999.

https://doi.org/10.1080/00401706.1999.10485931

[27] Plackett, R. L., Burman, J. P. "The Design of Optimum Multi factorial Experiments." Biometrika. 34, pp. 255-272. 1946. https://doi.org/10.2307/2332195

[28] Khajeh, M. "Response surface modeling of lead pre-concentration from food samples by miniaturized homogeneous liquid-liquid solvent extraction: Box- Behnken design." Food Chemistry. 129(4), pp. 18321838. 2011.

https://doi.org/10.1016/j.foodchem.2011.05.123

[29] Rostamian, H., Lotfollahi, M. N. "New Functionality for Energy Parameter of Redlich-Kwong Equation of State for Density Calculation of Pure Carbon Dioxide and Ethane in Liquid, Vapor and Supercritical Phases." Periodica Polytechnica Chemical Engineering. 60(2), pp. 93-97. 2016. https://doi.org/10.3311/PPch.8221

[30] Lotfizadeh Dehkordi, B., Ghadimi, A., Metselaar, H. S. C. "Box-Behnken experimental design for investigation of stability and thermal conductivity of $\mathrm{TiO}_{2}$ nanofluids." Journal of Nanoparticle Research. 15, pp. 1369, 2013.

https://doi.org/10.1007/s11051-012-1369-4 